\title{
Post-mortem study of the hip joint
}

\section{Correlations between observations}

\author{
P. D. BYERS, C. A. CONTEPOMI, AND T. A. FARKAS
}

From the Institute of Orthopaedics, Royal National Orthopaedic Hospital, 234 Great Portland Street, London WIN 6AD

\begin{abstract}
Byers, P.D., Contepomi, C. A., and Farkas, T. A. (1976). Annals of the Rheumatic Diseases, 35, 122-126. Post-mortem study of the hip joint. III. Correlations between observations. Correlations between alterations in hip joints, described in a post-morten study, have established the independence of limited and progressive alterations, and in addition have shown that there is a weak association between limited alterations and osteophytes and a strong one between progressive alterations and osteophytes. Nevertheless limited alterations may rarely undergo progressive damage. Cysts relate strongly to osteophytes but only moderately with progressive alterations. Limited alterations of both head and acetabulum can be subdivided. Some implications of these findings are discussed.
\end{abstract}

In an earlier macroscopical study, and a subsequent histological one, of 375 right hip joints and 155 left femoral heads from a post-mortem population (Figure) three main categories of articular cartilage alterations were described (Byers, Contepomi and Farkas, 1970, 1976) and histological distinction was made between the second and third. The three categories are (1) osteophytes; (2) limited alternations, which rarely lead to bone exposure and do not deform the joint; and (3) progressive alterations, always leading to bone exposure and joint deformity.

In 1970 we proposed on the basis of prevalence that the limited alterations, which were the most numerous, and the progressive alterations, which were the least common, were independent, and that only the latter was responsible for clinical osteoarthrosis. We were uncertain about the significance of osteophytes in relation to these.

Investigations by Foss and Byers (1972) and Byers and others (1974), of hip joints from populations who never or rarely develop primary osteoarthrosis in the hip joint showed that limited alterations and osteophytes were common. This supported the above hypothesis and led to a further hypothesis that the presence of osteophytes does not necessarily mean that progressive lesions are present or will occur. We then established correlations between

Accepted for publication July 29, 1975.

Correspondence to Dr. P. D. Byers. the cartilage alterations in the post-mortem specimens and studied their implications.

\section{Methods}

In the 1970 classification each of the three categories were subdivided, some subdivisions representing anatomically distinct lesions, and the others hopefully contributing to subsequent correlative analysis. Some subdivisions were later dropped as being insignificant and others were amalgamated. Those with which this study began are shown in the Figure. Subchondral cysts were also included.

Grades of severity of each alteration (Byers and others, 1970) had to be eliminated and finally only 'present' or 'absent' could be used for reliable analysis, and the correlations were studied with $2 \times 2$ tables. From this the $\mathbf{P}$ value was calculated using the $\chi^{2}$ test with Yates's correction (Armitage, 1971), and Yule's coefficient, Q, was calculated (Yule and Kendall, 1950). These two calculations were used because whereas the $\chi^{2}$ shows the reality of the correlation between two attributes it says nothing about its intensity, and Yule's coefficient, for which the standard deviation can be calculated, does. The calculation makes the use of the reciprocal of the values in the cells, thereby making allowance for any small numbers. $Q$ ranges from -1 to +1 to cover negative and positive associations.

The foregoing methods were applied to correlations within the head, within the acetabulum, between head and acetabulum, and between right and left heads. 


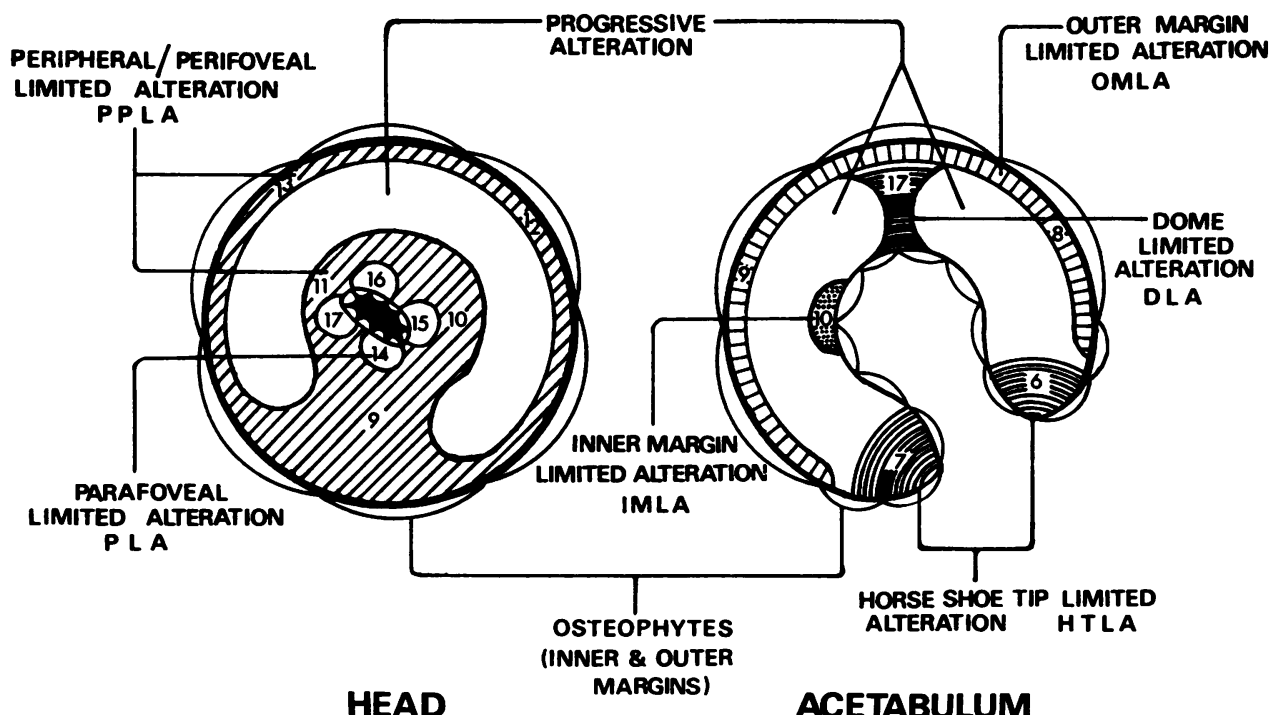

FIGURE Classification of articular cartilage alterations on a schematically represented right hip joint, with a medial view of the head and a lateral view of the acetabulum. The numbers identify subdivisions of the group of limited alterations in Byers and others (1970).

\section{Results}

By testing each original subdivision (Figure) against every other, it was possible to form the larger, more meaningful subcategories illustrated in the Figure. These were then tested against one another and the results are presented in Tables I-III.

\section{OSTEOPHYTES}

Osteophytes of the inner and outer margin correlate strongly $(P<0.0005 ; Q=0.75 \pm 0.07$ and better $)$ within the head and acetabulum and are treated as amalgamated groups. The strong cross-correlation of these is seen in Table III. They are strongly associated with subchondral cysts, particularly in the acetabulum $(P<0.0005 ; Q=0.639 \pm 0.107)$. There are also very strong associations with progressive lesions $(\mathrm{P}<0.0005$; minimum value of $Q=0.811 \pm$ 0.091 ). The relationships with limited alterations are discussed below.

\section{LIMITED ALTERATIONS}

The correlations based on the $\mathbf{1 9 7 0}$ divisions showed a range of positive associations between most divisions both within and between head and acetabulum. The capital subfoveal division and the acetabular peripheral ones were positively associated with osteophytes, and the latter with cysts. None correlated positively with the progressive category, but the dome alteration of the acetabulum had a negative association. When all relations were considered in the light of the histological findings (Byers and others, 1976) a number of amalgamations of the original divisions followed as shown in the Figure. A greater collapse is reasonable, even to the point of a single category for the joint (Table IV), but something is lost in the anonymity of amalgamation. The subcategories were used for the further analyses given in Tables I-III. The anatomically contiguous and histologically similar alterations originally numbered $9-13$, are inter-related

Table I Correlations between categories of articular cartilage alterations and cysts within the head

\begin{tabular}{|c|c|c|c|c|}
\hline & Cysts & Osteophytes & $P P L A$ & $P L A$ \\
\hline Osteophyte & $\begin{array}{l}<0.001 * \\
0.535+0.146 t\end{array}$ & & & \\
\hline PPLA & $<0.950$ & $<0.40$ & & \\
\hline PLA & $<0.70$ & $\begin{array}{l}0.159 \pm 0.181 \\
<0.40 \\
0.110+0.140\end{array}$ & $\begin{array}{l}<0.005 \\
0.399+0.135\end{array}$ & \\
\hline Progressive & $\begin{array}{l}<0.0005 \\
0.728 \pm 0.136\end{array}$ & $\begin{array}{l}<0.0005 \\
0.891 \pm 0.062\end{array}$ & $-0.557 \pm 0.180$ & $\begin{array}{l}<0.50 \\
0.771 \pm 0.221\end{array}$ \\
\hline
\end{tabular}

PPLA and PLA refer to limited alterations (see Figure and text). $*$ value for the $\chi^{2}$ test; Yules coefficient $Q \pm S D$. 
Table II Correlations between categories of articular cartilage alterations and cysts within the acetabulum

\begin{tabular}{|c|c|c|c|c|c|c|}
\hline & Cysts & Osteophytes & HTLA & $O M L A$ & $I M L A$ & $D L A$ \\
\hline Osteophyte & $\begin{array}{l}<0.0005 \\
0.639+0.107\end{array}$ & & & & & \\
\hline HTLA & $\begin{array}{l}<0.950 \\
-0.035+0.150\end{array}$ & $\begin{array}{l}<0.60 \\
0.060+0.168\end{array}$ & & & & \\
\hline OMLA & $\begin{array}{l}<0.0005 \\
0.451+119\end{array}$ & $\begin{array}{l}<0.001 \\
0.483+0.132\end{array}$ & $\begin{array}{l}<0 \cdot 20 \\
0.128+0.107\end{array}$ & & & \\
\hline IMLA & $\begin{array}{l}<0.60 \\
0.065 \pm 0.168\end{array}$ & $\begin{array}{l}<0.30 \\
0.183 \pm 0.178\end{array}$ & $\begin{array}{l}<0.40 \\
0.106 \pm 0.125\end{array}$ & $\begin{array}{l}<0.0005 \\
0.516 \pm 0.084\end{array}$ & & \\
\hline DLA & $\begin{array}{l}<0.050 \\
0.743+0.154\end{array}$ & $\begin{array}{l}<0.025 \\
-0.403+0.142\end{array}$ & $\begin{array}{l}<0.001 \\
0.398+0.110\end{array}$ & $\begin{array}{l}<0.01 \\
0.323+0.113\end{array}$ & $\begin{array}{l}<0.025 \\
0.325+0.140\end{array}$ & \\
\hline Progressive & $\begin{array}{l}<0.005 \\
0.564 \pm 0.184\end{array}$ & $\begin{array}{l}-0.403 \pm 0.142 \\
<0.0005 \\
0.854 \pm 0.072\end{array}$ & $\begin{array}{l}<0.80 \\
-0.031 \pm 0.264\end{array}$ & $\begin{array}{l}0.323 \pm 0.113 \\
0.05 \\
0.436 \pm 0.214\end{array}$ & $\begin{array}{l}<0.20 \\
-0.648 \pm 0.302\end{array}$ & $\begin{array}{l}<0.0005 \\
-0.734 \pm 0.128\end{array}$ \\
\hline
\end{tabular}

HTLA, OMLA, IMLA, DLA refer to limited alterations (see Figure and text).

Table III Correlations between head and acetabulum of categories of articular cartilage alterations

\begin{tabular}{|c|c|c|c|c|c|c|}
\hline & te & $T L A$ & $M L A$ & $M L A$ & $D L A$ & Progressive \\
\hline $\begin{array}{l}\text { steophyte } \\
\text { PLA } \\
\text { LA } \\
\text { rogressive }\end{array}$ & $\begin{array}{l}<0 \cdot 0005 \\
0 \cdot 660 \pm 0 \cdot 101 \\
<0 \cdot 30 \\
-0 \cdot 256 \pm 0 \cdot 184 \\
<0 \cdot 50 \\
-0 \cdot 181 \pm 0 \cdot 180 \\
<0 \cdot 0005 \\
0 \cdot 811 \pm 0 \cdot 091\end{array}$ & $\begin{array}{l}<0.95 \\
-0.011 \pm 0.141 \\
<0.0005 \\
0.643 \pm 0.111 \\
<0.80 \\
-0.048 \pm 0.114 \\
<0.90 \\
-0.031 \pm 0.264\end{array}$ & $\begin{array}{l}<0.0005 \\
0.649 \pm 0.086 \\
<0.01 \\
0.379 \pm 0.134 \\
<0.0005 \\
0.429 \pm 0.093 \\
<0.05 \\
0.463 \pm 0.214\end{array}$ & $\begin{array}{l}<0 \cdot 20 \\
0 \cdot 198 \pm 0 \cdot 147 \\
<0 \cdot 40 \\
0 \cdot 130 \pm 0 \cdot 171 \\
<0 \cdot 20 \\
0 \cdot 189 \pm 0 \cdot 124 \\
<0 \cdot 20 \\
-0 \cdot 698 \pm 0 \cdot 302\end{array}$ & $\begin{array}{l}<0 \cdot 80 \\
-0 \cdot 064 \pm 0 \cdot 151 \\
<0 \cdot 0005 \\
0 \cdot 551 \pm 0 \cdot 101 \\
<0 \cdot 10 \\
0 \cdot 234 \pm 0 \cdot 124 \\
<0 \cdot 0005 \\
-0 \cdot 734 \pm 0 \cdot 128\end{array}$ & $\begin{array}{l}<0.0005 \\
0.887 \pm 0.063 \\
<0 \cdot 025 \\
-0.612 \pm 0.164 \\
<0.05 \\
0.779 \pm 0.204 \\
<0.0005 \\
1 \cdot 0\end{array}$ \\
\hline
\end{tabular}

Table IV Correlations for articular cartilage alterations and cysts for the joint as a whole

\begin{tabular}{|c|c|c|c|}
\hline & Cyst & Osteophytes & Limited \\
\hline $\begin{array}{l}\text { Oesto- } \\
\text { phyte } \\
\text { Limited }\end{array}$ & $\begin{array}{l}<0.025 \\
0.300 \pm 0.132 \\
<0.005 \\
-0.527 \pm 0.140\end{array}$ & $\begin{array}{l}<0.05 \\
0.450 \pm 0.248\end{array}$ & \\
\hline $\begin{array}{l}\text { Progress- } \\
\text { ive }\end{array}$ & $\begin{array}{l}<0.05 \\
0.447 \pm 214\end{array}$ & $\begin{array}{l}<0.0005 \\
0.894 \pm 0.066\end{array}$ & $\begin{array}{l}<0.90 \\
-0.221 \pm 0.371\end{array}$ \\
\hline
\end{tabular}

(P $<0.0005$, and a minimal $Q=0.512 \pm 0.052$ ), forming a single subcategory, 'peripheral-perifoveal limited alteration' (PPLA). The parafoveal, histologically uniform alterations 14-17 form a second subcategory (PLA). These two are strongly associated $(\mathrm{P}<0.005, Q=0.399 \pm 0.135)$ (Table I). In the acetabulum the alterations at the tips of the horseshoe (HTLA) associate strongly ( $<<0.0005, Q=0.671 \pm$ $0.084)$. The other subcategories are the outer margin (OMLA), the inner margin (IMLA), and the dome (DLA) (Table II). All these were inter-related except HTLA with the outer and inner alterations.

Half the cross-correlations between subcategories in head and acetabulum are significant (Table III). Only IMLA is not involved. Notable is the intense PPLA/HTLA association. The first analysis showed that the perifoveal element of PPLA is responsible, in particular its posterior component with the matching component of HTLA $(\mathrm{P}<0.0005, Q=$ $0.596 \pm 0.099$ )

The only instance of a significant positive correlation between limited alterations and subchondral cysts was found when the former were treated separately. The outer acetabular alteration correlated with cysts $(\mathrm{P}<0.005 ; Q=0.409 \pm 0.122)$. But there were others in which $\chi^{2}$ was not significant, but $\mathrm{Q}$ was negative. These dominate the amalgamations as shown by PPLA, HTLA, as listed in Tables I, II, and IV.

Limited alterations did not correlate with progressive alterations unless the former were treated singly when some had significant negative values of which the strongest was the alteration in the dome of the acetabulum $(\mathrm{P}<0.0005 ; \mathrm{Q}=-0.734 \pm 0 \cdot 128)$.

\section{PROGRESSIVE ALTERATIONS}

The correlations with osteophytes, and cysts (very strong), and with limited alterations (none or negative) have been described.

\section{CYSTS}

It is worthwhile stating that there were 29 cysts recorded in the head and 56 in the acetabulum $(P<0.005 ; Q=0.549 \pm 0.147)$. The number of cysts in the acetabular rim was 30 . As stated above, there is a 
strong association with osteophytes and progressive alterations, and with OMLA.

\section{ALTERATIONS BETWEEN RIGHT AND LEFT HEADS}

Each class of alteration was strongly associated in paired heads. The $P$ value was always $<0.0005$, and $Q$ ranged from $0.539 \pm 0.122$ for osteophytes to $0.974 \pm 0.024$ for progressive alterations.

\section{Conclusions and discussion}

These findings and others from related studies of hip joints and femoral heads (Byers and others 1970, 1974, 1976; Foss and Byers, 1972) refute the hypothesis of Harrison, Schajowicz, and Trueta (1953) that all the articular cartilage changes of the hip joint are osteoarthrotic. The evidence points instead to three kinds of degenerative articular cartilage alterations, one of which is responsible for osteoarthrosis, if this is defined as a progressive disorder in which articular cartilage is exposed and the joint deformed. Although this is strongly associated with osteophytes, the latter are not a sine qua non, nor does their presence necessarily indicate that osteoarthrosis is present or will occur.

In 1970 we suggested that the limited alterations were due to aging. But by definition age changes should affect all the population, and this is clearly not so. They must be regarded as age-related degenerative disorders of cartilage. Since this is different from progressive alterations and has either no correlation or a weak negative correlation with progressive alterations, there must be at least two degenerative joint disorders. Since osteophytes can occur without progressive alterations and are not associated with limited alterations, it seems reasonable to include them as a third class.

A simple demonstration of the relations between these categories is obtained when all the data are consolidated into the four categories, cysts, osteophytes, limited, and progressive, of the joint as a whole. From each $2 \times 2$ table can be calculated, in addition to $\chi^{2}$ and $Q$ the percentage of specimens with one class of alteration which shows any of the others (Table V). Thus although there is a strong association between osteophytes and pro-

Table $\mathrm{V}$ Each cell shows the percentage of all specimens with the alteration on the left which also had the alteration of the column heading

\begin{tabular}{|c|c|c|c|c|}
\hline & Cyst & Osteophyte & Limited & Progressive \\
\hline $\begin{array}{l}\text { Cyst } \\
\text { Osteophyte }\end{array}$ & $\overline{28}$ & 32 & 82 & $\begin{array}{r}8 \\
16\end{array}$ \\
\hline $\begin{array}{l}\text { Osteophyte } \\
\text { Limited }\end{array}$ & $\begin{array}{l}28 \\
17\end{array}$ & $\overline{23}$ & 96 & $\begin{array}{r}10 \\
4\end{array}$ \\
\hline Progressive & 38 & 81 & 88 & 一 \\
\hline
\end{tabular}

gressive alterations only $30 \%$ of cases with osteophytes are affected by the latter.

The implications of this for the radiological diagnosis of hip joint disease is illustrated by the radiologist's report on pelvic $x$-rays of 146 cadavers whose hip joints were studied, taken in conjunction with hand $x$-rays to define the population with respect to joint disorders. The correlation of his recognition of osteoarthrotic changes with the anatomical findings of osteophytes was very strong $(P<0.005 ; Q=0.677 \pm 0.121)$ but was not significant with progressive alterations $(P<0.30 ; Q=$ $0.611 \pm 0.448)$. Every radiologist must recognize this problem, to which attention was drawn by Danielsson (1964) in his study of the natural history of coxarthrosis in Malmö. Eighty-six patients labelled 'coxarthrosis' on the basis of osteophytes alone were followed for 11 years, and only one showed joint space narrowing. Since the presence of osteophytes and cysts does not demand a diagnosis that implies a disorder so serious as osteoarthrosis, and since progressive destructive cartilage changes are the essential features of osteoarthrosis, and it is only these that are likely to give rise to joint narrowing, it is obvious that strict criteria for its recognition at various sites in $x$-rays are necessary. This seems to be the only way that precision in the earlier radiological diagnosis of osteoarthrosis can be achieved.

The results of the study stimulate some thoughts about the pathogenesis of osteoarthrosis. The strong negative association between the limited acetabular dome alteration and progressive alterations directs attention to this relation. Day, Freeman, and Swanson (1975) found that unusually high loads are borne by some acetabulae at this site. Perhaps some cases of osteoarthrosis begin with this limited acetabular change, a hypothesis advocated by Bullough, Goodfellow, and O'Connor (1973). The sequence of events envisaged is that the limited alteration in the dome comes into excessive contact with the head as the incongruity of the acetabulum diminishes with age, which sets up a progressive alteration in the head that ultimately reacts upon the acetabulum. Inherent in this view is the idea that limited changes are the consequence of a restricted demand for load carriage. Attention is drawn to the high correlation between posteroinferior elements of PPLA and HTLA (Figure, Table III, and text). These were infrequently found to be the site of bone exposure, but if extensive, must be regarded as progressive (Byers and others, 1970, Fig. 5D), and can probably be accounted for by proposing that circumstances in some individuals occasion demand for load carriage on the limited alterations with a consequential change to progressive behaviour.

The work for this and the other papers relating to the hip joint has been carried out with the financial support 
of the Arthritis and Rheumatism Council which is gratefully acknowledged. The material for this study was obtained through the kind cooperation of Professor I. Doniach and the members of his department at the London Hospital Medical School. Dr. L. J. Rae, Senior Radiologist of the London Hospitals at the time of the study, arranged for the radiographs of the cadavers and reported on these. Miss V. Brodie, chief radiographer, cheerfully persisted under often difficult circumstances and was chiefly responsible for the many films taken both by herself and her colleagues. Mr. Peter Fayers patiently discussed the statistical analysis. Mr. Terry Davis provided the illustrations. We are very grateful for their help and co-operation and happy to be able to acknowledge it here.

\section{References}

Armitage, P. (1971) In 'Statistical Methods in Medical Research'. Blackwell Scientific Publications, Oxford

Bullough, P. G., Goodfellow, J. W., ANd O'Connor, J. (1973) J. Bone Jt Surg., 55B, 746 (The relationship between degenerative changes and load bearing in the human hip)

Byers, P. D., Contepomi, C. A., AND Farkas, T. A. (1970) Ann. rheum. Dis., 29, 15 (A post mortem study of the hip joint ; including the prevalence of the features of the right side)

$-,-1,(1976)$ Ibid., 35, 114 (Post-mortem study of the hip joint. II. Histological basis for limited and progressive cartilage alterations)

-, Hoaglund, F. T., Purewal, G. S., and Yau, A. C. M. C. (1974) Ibid., 33, 157 (Articular cartilage changes in Caucasian and Asian hip joints)

Danielsson, L. G. (1964) Acta Orthop. Scand., Suppl. 66 (Incidence and prognosis of coxarthrosis)

Day, W. H., Freeman, M. A. R., AND Swanson, S. A. V. (1975) J. Bone Jt Surg., 57B, 302 (Contact pressures in the loaded human cadaver hip)

Foss, M. V., AND BYers, P. D. (1972) Ann. rheum. Dis., 31, 259 (Bone density and osteoarthrosis)

Harrison, H. M. M., Schajowicz, F., and Trueta, J. (1953) J. Bone Jt Surg., 35B, 598 (Osteoarthritis of the hip: a study of the nature and evolution of the disease)

Yule, M. G., AND Kendall, G. V. (1950) In 'An Introduction to the Theory of Statistics', 14th ed. Griffin, London 